\title{
ITINERÂNCIAS FORMATIVAS: ESTÁGIO E PRÁTICAS EM CONTEXTOS DE APRENDIZAGENS COLABORATIVAS
}

\author{
ITINERANCIAS FORMATIVAS: FORMACIÓN Y PRÁCTICAS EN CONTEXTOS DE \\ APRENDIZAJE COLABORATIVO
}

\section{TRAINING ITINERANCIES: INTERNSHIP AND PRACTICE IN COLLABORATIVE LEARNING CONTEXTS}

\author{
Marilene Batista da Cruz NASCIMENTO ${ }^{1}$ \\ Mateus Henrique Silva SANTOS ${ }^{2}$ \\ Josevânia Teixeira GUEDES ${ }^{3}$
}

RESUMO: Este estudo apresenta as ações relacionadas ao estágio e às práticas em contextos profissionais na formação universitária das licenciandas do curso de Pedagogia, da Universidade Federal de Sergipe/Campus Professor Alberto Carvalho, inserindo-se no componente curricular Estágio Supervisionado IV, com vistas a discutir sobre as itinerâncias e a apropriação de aprendizagens em redes colaborativas para a atuação no campo da gestão e dos diferentes espaços e tempos pedagógicos da escola básica numa abordagem inter e transdisciplinar. A trilha metodológica seguiu os princípios da intervenção, baseada em problemáticas do cotidiano de cinco unidades de ensino públicas das redes estadual e municipal, envolvendo a participação de 23 estagiárias e o apoio de membros do PET Educação - Conexão de Saberes, do Grupo de Aprendizagem e Ensino de Física (GAEF) e do Grupo de Pesquisa Relicário. Os resultados sinalizaram que as itinerâncias formativas (re)construídas pelos envolvidos promoveram impactos no campo do desenvolvimento humano e social das escolas e da própria UFS, haja vista aproximar as diversas realidades, potencializar o trabalho colaborativo, criar espaços de diálogos e autonomia entre os atores.

PALAVRAS-CHAVE: Aprendizagens colaborativas. Estágio. Formação inicial. Práticas.

RESUMEN: Este estudio presenta las acciones relacionadas con la pasantía y las prácticas en contextos profesionales en la formación universitaria de los estudiantes de pregrado del curso de Pedagogía de la Universidad Federal de Sergipe/Campus Profesor Alberto Carvalho, insertadas en el componente curricular Pasantía Supervisada IV, con el fin de discutir las itinerancias y la apropiación del aprendizaje en redes de colaboración para el desempeño en el campo de la gestión y los diferentes espacios y tiempos pedagógicos de la

\footnotetext{
${ }^{1}$ Universidade Federal de Sergipe (UFS), São Cristóvão - SE - Brasil. Professora Adjunta do Programa de Pósgraduação em Educação (PPGED) e da Graduação pelo Departamento de Educação/Campus Professor Alberto Carvalho. Tutora bolsista do PET Educação - Conexão do Saberes (UFS/FNDE). Doutorado em Educação (PUCRS). ORCID: https://orcid.org/0000-0002-6671-7907. E-mail: nascimentolene@yahoo.com.br

${ }^{2}$ Universidade Federal de Sergipe (UFS), São Cristóvão - SE - Brasil. Mestre em Educação pelo Programa de Pós-graduação em Educação (PPGED). ORCID: https://orcid.org/0000-0001-5862-018X. E-mail: mateus.santos27@hotmail.com

${ }^{3}$ Faculdade Pio Décimo (FPD), Aracaju - SE - Brasil. Professora dos cursos de licenciatura em Química e Pedagogia. Doutorado em Educação (UNIT). Bolsista pelo Programa Residência Pedagógica (Capes). ORCID: https://orcid.org/0000-0003-3809-915X. E-mail: josevaniatguedes@gmail.com
} 
escuela básica en un enfoque inter y transdisciplinario. El recorrido metodológico siguió los principios de la intervención, basada en los problemas cotidianos de cinco unidades de enseñanza pública de las redes estatal y municipal, con la participación de 23 aprendices y el apoyo de los miembros del PET Educación - Conexión del Conocimiento, del Grupo de Aprendizaje y Enseñanza de la Física (GAEF) y del Grupo de Investigación Relicário. Los resultados indican que los itinerarios formativos (re)construidos por los involucrados promovieron impactos en el ámbito del desarrollo humano y social de las escuelas y de la propia UFS, dado el acercamiento de las diversas realidades, potenciando el trabajo colaborativo, creando espacios de diálogo y autonomía entre los actores.

PALABRAS CLAVE: Aprendizaje colaborativo. Prácticas. Formación inicial. Prácticas.

ABSTRACT: This study presents the actions related to the internship and the practices in professional contexts in the university education of undergraduate students of the course of Pedagogy at the Federal University of Sergipe/Campus Professor Alberto Carvalho, inserted in the curricular component Supervised Internship IV, in order to discuss the itinerancies and the appropriation of learning in collaborative networks for the performance in the field of management and the different pedagogical spaces and times of the basic school in an inter and transdisciplinary approach. The methodological path followed the principles of intervention, based on the daily problems of five public schools of the state and municipal networks, involving the participation of 23 trainees and the support of members of PET Education - Knowledge Connection, the Physics Learning and Teaching Group (GAEF) and the Relicário Research Group. The results indicated that the formative itinerancies (re)built by those involved promoted impacts in the field of human and social development of the schools and the UFS itself, given the approximation of the various realities, enhancing collaborative work, creating spaces for dialogue and autonomy among the actors.

KEYWORDS: Collaborative learning. Internship. Initial training. Practices.

\section{Considerações iniciais}

Este estudo foi desenvolvido no curso de Licenciatura em Pedagogia da Universidade Federal de Sergipe (UFS), Campus Professor Alberto Carvalho, apoiado nas pesquisas do Grupo de Estudos em Educação Superior (GEES/UFS/CNPq), especificamente, na investigação em andamento "Formação de Professores, Saberes e Práticas Educativas no Campo da Pesquisa Intervenção", que se fundamenta no exercício da docência, inspirada na formação científico-pedagógica abalizada no processo de ação e reflexão, tendo como objetivo articular trabalhos relacionados à pesquisa-intervenção, aos saberes e às práticas educativas, com vistas à produção e difusão de conhecimento.

O GEES envolve doutores, doutorandos, mestres, mestrandos, bolsistas de iniciação científica, especialistas, graduados e graduandos, professores da educação básica e superior, que se propõem investigar a educação superior em três linhas: a) Formação de Professores: 
saberes e práticas na educação básica; b) Pedagogia Universitária: campo de prática, formação e tecnologias educacionais; c) Avaliação, Qualidade e Iniciação à Pesquisa na Educação Superior. Assim, os estudos contemplam temas relacionados à educação como direito subjetivo, visando discutir sobre permanência, acesso e promoção da igualdade, a qual se baseia na equidade no âmbito do desenvolvimento humano e social, contribuindo com apropriação de saberes e fazeres próprios da docência, tornando possível, inclusive, compreender como se constroem as itinerâncias formativas de professores e licenciandos.

O termo itinerância, aqui, compreende um processo formativo marcado por incursões que sustentam a valorização das experiências de vida, as trajetórias e os caminhos percorridos pelos participantes, que teceram as identidades da profissão tendo como base o conhecimento de si a partir da formação engendrada nas subjetividades da própria prática. Nessa configuração, os estágios permitem uma aproximação com a realidade por meio de teorias, fundamentação conceitual-metodológica, diálogo e intervenção como práxis transformadora.

$\mathrm{Na}$ perspectiva de indissociabilidade entre pesquisa, ensino e extensão, adotou-se a concepção do professor como profissional reflexivo e da reflexão-na-ação como estratégia que fundamenta a epistemologia da prática, tanto do ponto de vista da pesquisa didática, quanto dos cenários da profissão. Defende-se, assim, uma formação docente pautada no processo educativo, cultural e científico, sustentando a teoria e a prática como condição para a interação entre universidade, sociedade e escola. Essa conjuntura estabelece a ressignificação de saberes sistematizados, acadêmico e popular, para a produção do conhecimento resultante do confronto com a realidade da sala de aula da educação básica, em especial, no campo dos estágios supervisionados curriculares e das práticas pedagógicas em contextos de aprendizagens colaborativas na educação infantil, no ensino fundamental (anos iniciais) e médio, entre cinco escolas públicas das redes estadual e municipal.

O estágio constitui-se um caminho para a promoção de uma formação de professores apoiada no marco teórico-metodológico transdisciplinar ${ }^{4}$, visando à potencialização do desenvolvimento integral de pessoas, da construção da autoria do futuro docente como um pesquisador protagonista. Esse aspecto remete à crescente preocupação das universidades frente ao distanciamento entre o ensino superior e a educação básica. Tanto na graduação quanto na pós-graduação reclama-se da dissociação entre forma e conteúdo, teoria e prática.

${ }^{4}$ De acordo com Morin (2000), a transdisciplinaridade é uma prática que une e não separa o múltiplo e o diverso no processo de construção do conhecimento, englobando a avaliação para pressupor a utilização de diversas linguagens à mediação das aprendizagens nas dimensões dos conteúdos da disciplina e da compreensão do todo e não apenas das partes. 
Destaca-se, então, que essa experiência relacionou formação inicial de professores e estágios curriculares com aprendizagens em redes de conhecimento, possibilitando trabalhar com a epistemologia dos saberes e fazeres da docência, bem como a formação do espírito científico. Tardif (2014) discute que esses saberes não se reduzem a processos mentais, mas, sim, a um saber social manifestado nas relações complexas entre educadores e educadores, educadores e discentes, discentes e discentes. Essa proposta defende a ideia de uma formação universitária para além da visão que reduz os professores à condição de objetos de estudo, de modo que sejam considerados sujeitos críticos e reflexivos, valorizando a mediação na docência e a professoralidade.

Defende-se, ainda, que os docentes são profissionais aprendentes e não implementadores de teorias ou impedimentos para mudanças, já que as aprendizagens colaborativas permitem diferentes formas de ensinar e aprender de um professor pesquisador. Bachelard (1978) vê esse instinto formativo como uma das condições necessárias à formação, podendo atuar por meio de uma prática reflexiva e um constante aprender a ensinar. Isso significa que a docência se configura pela problematização do trabalho na escola, sendo, portanto, marcada pela reflexão contínua, em que a aprendizagem do professor é definida como uma dinâmica fundamentada pelo diálogo entre ação e reflexão.

Nesse sentido, os estágios curriculares envolvem formação identitária epistemológica, constituindo-se de um campo específico de intervenção profissionalizante a partir de uma prática social. Essa perspectiva ultrapassa os princípios da didática por permear a intencionalidade do ensinar e permitir mudanças nos sentidos e significados das aprendizagens colaborativas dos futuros professores. Essas aprendizagens são entendidas como processo ativo que se dá pela construção entre os pares e os papéis do grupo, que são definidos pelo próprio grupo, e a autoridade compartilhada, sendo o docente um mediador: a centralização do apreender recai no educando, que fortalece a corresponsabilidade e as redes ${ }^{5}$ de conhecimento (TORRES; IRALA, 2014). Ou seja, as redes têm função determinante nos processos de ensinar e aprender, sustentando os estágios na abordagem inter e transdisciplinar.

Nesse contexto, este artigo tem como objetivo apresentar as ações relacionadas ao estágio e às práticas em contextos profissionais na formação universitária de licenciandas de Pedagogia, com vistas a discutir sobre as itinerâncias e a apropriação de aprendizagens em

${ }^{5}$ Nesta pesquisa, “[...] as redes não são expedientes instrumentais para envolver pessoas e determinar caminhos ou orientações. Elas farão o que seus membros quiserem fazer em regime de colaboração, com vistas a aumentar a interação, sem a existência de centralismo" (NASCIMENTO; OLIVEIRA, 2019, p. 673). 
redes colaborativas para a atuação no campo da gestão e dos diferentes espaços e tempos pedagógicos da escola básica.

\section{Contextualização da proposta interventiva}

O estágio na formação inicial docente é uma prática de ensino que problematiza e investiga os fatos e os fenômenos para uma possível intervenção sustentada pela reflexãoação-reflexão, sendo necessária a compreensão dos sentidos e princípios da profíssão. Esse tipo de proposta fundamenta-se na indissociabilidade entre teoria e prática, voltada à dialogicidade e descoberta de caminhos para as aprendizagens em redes na educação básica; além disso, o estágio de gestão também segue o pressuposto da responsabilização pelo aprender a apreender dos estudantes, atentando-se para os processos de mediação de conhecimentos e saberes com o mundo, consigo e com o outro.

Isso representa uma formação universitária focada em multidimensões, capaz de integrar diferentes aprendizagens, a saber: a) desenvolvimento pessoal; b) conhecimentos culturais; c) habilidades relacionadas ao desempenho profissional ou à função específica; d) atitudes e valores reconhecidos socialmente; e e) enriquecimento experiencial (ZABALZA, 2014). Considerando esses eixos, esta intervenção foi desenvolvida nos espaços da UFS/Campus Professor Alberto Carvalho, pelo Departamento de Educação, que oferta o curso de Licenciatura em Pedagogia, especificamente, no componente curricular obrigatório de Estágio Supervisionado IV, com 75 horas-aula (30h teóricas e 45h práticas), no semestre letivo de 2019.2, ocorrido entre 14.10.2019 e 27.03.2020. As ações estenderam-se ao longo de toda a carga horária prática da disciplina - de janeiro a março de 2020 -, envolvendo 23 licenciandas que cursavam o $9^{\circ}$ período.

Trata-se de uma iniciativa pautada na transdisciplinaridade como prática que une e não separa o múltiplo e o diverso no processo de construção do conhecimento. À vista disso, partiu-se do pressuposto de diversas linguagens para a mediação da aprendizagem das acadêmicas, ressignificando as multidimensões dos conteúdos para uma compreensão do todo e não apenas das partes (MORIN, 2000). Assim, o planejamento, a execução e a avaliação fundamentaram-se numa formação reflexiva que permitiu equacionar as práticas, escolher temáticas problematizadoras, via diagnóstico da realidade das escolas, propor alternativas de intervenção, acompanhar as itinerâncias formativas das estagiárias que aproximaram o ensino superior à educação básica. 
Essa configuração garantiu o princípio do trabalho colaborativo, envolvendo as instituições das redes estadual e municipal, sendo quatro de Itabaiana (Escola Municipal Professora Neilde Pimentel Santos, Colégio Estadual Guilhermino Bezerra, Escola Estadual Eliezer Porto e Escola Municipal Professora Vera Cândida Costa de Santana) e uma em Moita Bonita, Colégio Estadual Djenal Tavares de Queiroz, ambas as cidades localizadas no estado de Sergipe. Essas unidades de ensino foram o lócus das ações de intervenção, revelando-se como espaço de formação e desenvolvimento profissional no âmbito dos eixos conceitual, metodológico e político. Para Pimenta e Lima (2008), o eixo conceitual aborda o estágio, tendo por base a reflexão da práxis docente, uma vez que o metodológico compreende uma perspectiva de procedimento para além do como fazer, do como elaborar e aplicar técnicas de ensino, e o eixo político é um território formativo em que a referência é a própria escola.

O desenvolvimento das ações de intervenção também contou com o apoio dos membros do PET Educação - Conexão de Saberes, que visa atender os princípios da indissociabilidade entre ensino, pesquisa e extensão, sendo formado por grupos tutoriais de aprendizagem; do Grupo de Aprendizagem e Ensino de Física ${ }^{6}$ (GAEF/UFS/CNPq), com a atividade "Física Show na Educação Básica", em que foram apresentados experimentos e abordagem de fenômenos físicos, além do Grupo de Pesquisa Redes de Leituras Inscritas: cultura letrada, apropriações, representações e operações do ato de $\operatorname{ler}^{7}$ (Relicário/UFS/CNPq), que tem duas linhas de pesquisa: a) História da leitura e cultura letrada; e b) Leitura, práticas de leitura e formação de leitores.

Essas parcerias permitem inferir que o estágio como atividade colaborativa promove a reflexão da prática estimulada pela interação entre os diferentes atores da universidade e da escola, especificamente, no campo da gestão escolar. A discussão aqui proposta conduz a (re)pensar sobre a relevância do professor ter a autonomia profissional para (re)criar a profissão docente pela formação e consolidação do espírito científico. Isso posto, possibilita afirmar que há uma relação intrínseca entre a ciência pedagógica, a prática reflexiva e a pesquisa como dispositivo para uma formação em que a práxis seja sustentada pelas experiências e pelas aprendizagens em redes de conhecimento.

Essas aprendizagens no campo do estágio envolveram proposições para a apreensão de conhecimento: a) experiência das licenciandas como fundamento da aprendizagem oportunidade é potencial para se aprender; b) construção ativa pela experiência - sujeitos

${ }^{6}$ Grupo liderado pelo Prof. Dr. Tiago Nery do Departamento de Física do Campus Professor Alberto Carvalho (DFI/UFS).

${ }^{7}$ Grupo coordenado pela Profa. Dra. Roselusia Teresa de Morais Oliveira do Departamento de Educação do Campus Professor Alberto Carvalho (DEDI/UFS).

RIAEE - Revista Ibero-Americana de Estudos em Educação, Araraquara, v. 16, n. 3, p. 1807-1822, jul./set. 2021. e-ISSN: 1982-5587 
apreendem ativamente pela vivência que decorre da transação entre o aprendiz e o meio, ou seja, a experiência é relacional; c) processo holístico - movimento sistêmico que envolve a intervenção do afetivo (sentimentos e emoções) e cognitivo (intelectual e cerebral); d) apropriação social e cultural - construção social e cultural por meio da linguagem; e e) influência do contexto socioemocional - manifestação da experiência pelo passado e presente (ZABALZA, 2014).

Considerando essas premissas, o Estágio Supervisionado IV (gestão escolar) foi um momento em que diversas variáveis se cruzaram e as aprendizagens de várias "cores" foram (re)construídas por meio da automotivação com respeito à ação de intervenção; vinculação do objeto aprendido com a situação nova (conteúdos específicos e metodologias); autoavaliação, com vistas a buscar o processo de autoanálise; entendimento da prioridade dos estudantes na gestão das atividades; captação da problemática; inserção das ações com base no saber e no fazer da escola (ZABALZA, 2014).

No conjunto da policromia das aprendizagens, teoria e prática foram indissociáveis por meio do planejamento, execução e avaliação de ações de gestão e coordenação pedagógica em cinco escolas da educação básica. Para tanto, as estagiárias trabalharam em equipes na elaboração de um projeto de intervenção direcionado aos seguintes conteúdos curriculares e metodológicos:

1) contextualização do campo de estágio - Levantamento de diagnóstico de problema(s) a partir de um roteiro norteador: como é a organização e o funcionamento da escola? Que aspectos históricos da instituição cabem ressaltar? Qual a faixa etária predominante dos estudantes? Quais os perfis socioeconômico e sociocultural desse público? Os alunos residem na comunidade próxima à escola? A escola conhece o perfil das famílias desses discentes? Como se caracteriza o desempenho escolar dos educandos? Como é o relacionamento dos estudantes com os professores e funcionários e vice-versa? Quais são as atividades escolares de maior interesse dos alunos? Como se caracteriza a formação inicial dos professores? Quais as políticas públicas adotadas pela escola? Que ações de formação continuada são desenvolvidas? Como se caracteriza a atuação da coordenação pedagógica da escola? Que recursos pedagógicos estão disponíveis?;

2) referencial teórico - Produção de texto polifônico sobre os aspectos conceituais orientados pelo(s) tema(s)/problema(s) definido(s) para a intervenção. A realização dessa etapa envolveu consulta a livros, artigos, teses, dissertações para selecionar teorias, conteúdos, políticas públicas, legislação. Fez-se necessário seguir a norma 10.520/2002 de 
citação da Associação Brasileira de Normas e Técnicas (ABNT) e apresentar linguagem científica, baseada na impessoalidade, objetividade, clareza, concisão e coerência;

3) objetivos (geral e específicos) - Elaboração das ações de intervenção, observando o(s) problema(s) mapeado(s) na etapa da contextualização e definição dos objetivos, usando verbo no infinitivo para apresentar, de forma clara, o que se pretende alcançar e anunciar os resultados esperados;

4) procedimentos metodológicos - Registro da trilha de execução do projeto, detalhando as etapas passo a passo. Nesse tópico, um plano de ação foi estruturado com descrições das atividades dentro de temáticas dirigidas à gestão escolar: EIXO 1 - Trabalho da equipe escolar e os caminhos para a aprendizagem do aluno; EIXO 2 - Ações do coordenador nos espaços e tempos pedagógicos; EIXO 3 - Formação continuada dos professores na escola; EIXO 4 - Processos de ensino e de avaliação da aprendizagem do aluno; EIXO 5 - Fortalecimento da escola na comunidade e como comunidade. Cada um dos planos indicava ações de intervenção, contendo: eixo; objetivo(s); carga horária; atividade (o quê?); local (onde?); estratégia(s) (como?); responsável (quem?); envolvidos; período (quando?); e recursos;

5) resultados esperados, acompanhamento e avaliação - Descrição dos potenciais reflexivos da intervenção alinhados aos objetivos, permitindo a mensuração, além disso, o registro do acompanhamento e avaliação da implementação do projeto, sinalizando os dispositivos utilizados. Assim, a finalidade desse tópico é a identificação de conquistas e ganhos, desafios enfrentados e soluções encontradas, perspectivas e possíveis propostas para a continuidade das ações.

Os conteúdos curriculares, trabalhados no espaço de atuação profissional das escolas básicas, submergiram de condições próprias que foram das afetivas e relacionais às funcionais e estéticas sobre clima e cultura escolar, como humanização pelo seu sentido social; fundamentos do Projeto político-pedagógico (PPP) e da autonomia; gestão participativa e democrática; implicações da coordenação pedagógica na aprendizagem das crianças e dos jovens; e formação continuada dos professores. Essa perspectiva respalda-se em aprendizagens pautadas na reflexão-ação-reflexão, as quais abrangem o cerne do processo educativo que reside no desenvolvimento humano e social, visando atender às características da sociedade e dos contextos inseridos nesta. Na condição de gerenciar dilemas, “[...] a consciência profissional consolida-se e desenvolve-se, explicitando-os, clarificando-os, estabelecendo as suas ligações, extraindo as derivações das [ações]" (SACRISTÁN, 1999, p. 
87) vivenciadas pela indissociabilidade entre conteúdos, aprendizagens colaborativas e experiências de intervenção.

Assim, os conteúdos apreendidos permearam conhecimentos científico-culturais e a mediação de linguagens plurais, mobilizando saberes disciplinares, curriculares, experienciais e de formação profissional (TARDIF, 2014), aportados na abordagem inter e transdisciplinar que compreende o olhar plural e fortalece os sistemas complexos das ações educativas pela dúvida, pelos questionamentos e pelo inacabamento e incompletude do ser humano.

Cabe ressaltar que as aprendizagens das licenciandas foram sustentadas em teorias e práticas, com vistas à constituição de sentidos e significados do trabalho docente. Então, esse processo permitiu a difusão de conhecimentos e saberes inerentes à formação profissional da docência pela necessidade de promover uma educação de qualidade baseada na equidade.

\section{Aprendizagens em rede de experiências}

Esta seção tem como objetivo apresentar os procedimentos didáticos utilizados para o desenvolvimento dos projetos de intervenção ${ }^{8}$, visando evidenciar as inter-relações entre o estágio - como campo do conhecimento além de um componente curricular, a formação docente e a policromia das aprendizagens como experiências e intervenção na realidade (práxis). Esse processo ocorreu após a elaboração dos projetos de intervenção executados a partir dos diagnósticos mapeados no campo da gestão escolar e do trabalho da coordenação pedagógica, conforme descrito no tópico anterior, contudo, as ações ocorreram em diferentes espaços de aprendizagens da universidade e das escolas básicas, envolvendo as licenciandas que contaram com o apoio dos bolsistas e voluntários do PET Educação, pertencentes a dois cursos de bacharelado em Administração e Sistemas de Informação e três acadêmicos dos cursos de Física, Letras Português e Pedagogia; os graduandos em Física vinculados ao GAEF, além dos membros do Grupo de Pesquisa Relicário. Assim, torna-se necessário registrar as itinerâncias formativas das participantes que tiveram suas identidades substituídas por nomes de flores, visando à garantia da confidencialidade.

$\mathrm{Na}$ Escola Estadual Eliezer Porto, o projeto "Espaços de Aprendizagens Colaborativas" focou na ideia de que a gestão escolar constitui uma dimensão objetiva para promover a organização, a mobilização e a articulação para garantir a aprendizagem dos alunos (LUCK, 2009). Após a mobilização dos professores regentes, da equipe diretiva e da

\footnotetext{
${ }^{8}$ No endereço do Instagram @seminario.estagio.dedi há vídeos produzidos pelas estagiárias com registro das
} experiências e aprendizagens (re)construídas ao longo das ações de intervenção. 
coordenação, foram desenvolvidas oficinas de Língua Portuguesa e Matemática na área de leitura, escrita e interpretação; cálculos matemáticos e raciocínio lógico das turmas do $4^{\circ}$ e $5^{\circ}$ anos do ensino fundamental. Esse laboratório de aprendizagem envolveu atividades como: jardim da leitura, montagem de palavras com sílabas, roda da interpretação, bingo matemático, esquentando a cabeça e trilha matemática. A classe foi organizada em equipes que ficavam em média 50 minutos em cada oficina, sendo realizadas, simultaneamente, com revezamento.

Nessa unidade de ensino, as estagiárias também mobilizaram a equipe escolar para desenvolvimento de atividades recreativas e dinâmicas corporais, visando à redução da violência física e verbal no recreio. As brincadeiras e os jogos foram construídos com material reciclável, como: jogo pés e mãos; pula elástico; jogo vai e vem; jogo de argolas; bambolês; amarelinha, na perspectiva de aumentar o respeito pelo outro e a consciência de si.

Essa ação envolveu todas as turmas do ensino fundamental, anos iniciais, promovendo interação entre os estudantes. Segundo a licencianda Rosa (2020), durante a semana do projeto, o objetivo foi alcançado, no entanto, não se teve continuidade pelo descuido com o material produzido, fazendo-se necessária a articulação da equipe pedagógica para transformar a ação como parte do cotidiano. Fica evidente que a coordenação tem função determinante nos processos de gestão para "[...] favorecer a construção de um ambiente democrático e participativo, onde se incentive a produção do conhecimento por parte da comunidade escolar, tendo como resultado [...] uma educação de qualidade [...]." (OLIVEIRA; GUIMARÃES, 2013, p. 102).

Nessa escola, ainda, outro projeto intitulado "Espaços de Aprendizagem e Mobilidade Escolar: descoberta do mundo por meio da leitura" foi executado com ações dirigidas à construção de uma Arara Literária para a Oficina Literária "O Tamanho da Gente", com o apoio dos membros do Grupo de Pesquisa Relicário. Essa proposta sustentou-se no argumento de que a gestão em educação "[...] constitui a coordenação de instituições e de processos de formação humana, como objeto tanto de pesquisa, quanto de docência e de prática." (FRANCO, 2006, p. 212). A Arara Literária foi construída com madeira, pregos e rodinhas para a locomoção dos livros da sala de leitura e, posterior, exposição nas turmas do $2^{\circ}$ ao $5^{\circ}$ ano, com rodas de conversa sobre literaturas e realização de dinâmicas sensoriais e motoras. A licencianda Jasmim afirma que esse trabalho teve o objetivo de promover formação leitora e aprendizagem significativa por meio da coordenação motora, do sentir o cheiro, do ouvir, do sentar em roda para se experimentar "[...] o mundo da leitura e a construção de uma escrita". De acordo com as licenciandas Gardênia, Hortênsia, Jasmim e Orquídea, o trabalho com a 
biblioteca independe das condições da escola e "[...] poderá iniciar com ações graduais e constantes, envolvendo num primeiro momento o corpo docente e a posteriori a comunidade escolar. [...] A biblioteca [e as salas] de leitura têm a funcionalidade de abranger tanto a formação do leitor, quanto o envolvimento do educando com o espaço escolar".

Na Escola Municipal Professora Neilde Pimentel Santos, o projeto "Ler, Pensar e Expressar" desenvolveu a Oficina "Espaços Gamificados de Aprendizagem9", realizada no Laboratório Interdisciplinar de Formação de Educadores (Life/UFS), com 25 crianças do $3^{\circ}$ ano do ensino fundamental. A programação envolveu dinâmicas, jogos analógicos (dama, xadrez, pega vareta, cubo mágico) e digitais (Nintendo, Gameboy e Mega Drive), sendo uma oportunidade de aprender um pouco de programação com o movimento global a Hora do Código, criado pela Code.org., como também foi ministrado o minicurso "Práticas Educativas na Perspectiva da Educação Inclusiva", com uma fonoaudióloga, que atendeu 12 professores e teve a finalidade de trabalhar conteúdos relacionados à inclusão de alunos com deficiência (AcD). Para a licencianda Dália, a discussão permeou as principais características das deficiências nas unidades de ensino, o uso de recursos pedagógicos de baixo custo, sendo alguns produzidos com material reciclável, e o debate sobre o trabalho colaborativo das docentes da classe comum e das salas de recursos multifuncionais (SRM). Essa ação ressaltou a relevância da gestão escolar e da coordenação pedagógica para apoiar o Atendimento Educacional Especializado (AEE) e transformar a escola em espaço de formação continuada em serviço.

Na Escola Municipal Professora Vera Cândida Costa de Santana, o projeto "Formação e Práticas de Leitura: intervenções pedagógicas em uma escola pública da rede municipal" desenvolveu uma formação continuada em serviço, intitulada Oficina "A Hora do Conto", com 20 professores e monitores da educação infantil e anos iniciais do ensino fundamental, tendo como objetivos: discutir a relevância da contação de histórias como estratégia ativa para a promoção de aprendizagem significativa; vivenciar atividades apontadas ao desenvolvimento da linguagem e da expressão corporal; estimular a utilização de histórias como proposta metodológica na prática pedagógica, com vistas a desenvolver habilidades nas dimensões conceituais, procedimentais e atitudinais. No ponto de vista das licenciandas Amarilis, Violeta, Tulipa e Petúnia, a direção e a coordenação podem ofertar formação ao longo do ano letivo para potencializar a ressignificação das práticas pedagógicas e promover aprendizagens significativas. Além disso, as futuras pedagogas reconhecem a necessidade de

9 Registros disponíveis em: https://www.instagram.com/p/B_NbQechJVI/?utm_source=ig_web_copy_link. Acesso em: 10 out. 2020. 
uma formação que atenda aos desafios da escola, partindo da "[...] concepção [de que] a docência $[. .$.$] não se restringe às atividades pedagógicas de sala de aula. O docente formado$ [...] deverá estar preparado para desenvolver todos os tipos de trabalho de natureza educativa" (VIEIRA, 2011, p. 148).

O projeto "Fundamental mesmo é Participar: ações voltadas à Escola Estadual Guilhermino Bezerra" trabalhou no campo da leitura e da história da educação. O projeto temático "Sacola Viajante" reorganizou o espaço da sala de leitura, confeccionou ficha de cadastro para o leitor e a carteirinha dos alunos. As atividades contemplaram as turmas do $4^{\circ} \mathrm{e}$ $5^{\circ}$ anos, por meio de uma roda de conversa, envolvendo as equipes gestora e pedagógica para criação de um grupo de incentivo à leitura. Foram utilizadas contação de histórias com a estratégia da roda de conversa para apresentação pessoal, musicalização, ilustração e socialização das produções dos alunos. No tocante ao evento sobre a história dessa escola, atualmente denominada Colégio Estadual Guilhermino Bezerra, as atividades contemplaram apresentação cultural, recitação do poema "As maravilhas de Itabaiana", composto por Jayne Gois (graduanda de Pedagogia). Em seguida, ocorreram as palestras "Educação e sua Importância", "A importância do Guilhermino Bezerra para cidade de Itabaiana" e relatos das vivências, dos avanços e das memórias sobre o Guilhermino Bezerra.

Por fim, apresenta-se o projeto "Identidade: o respeito às semelhanças e diferenças de si e do outro", desenvolvido no Colégio Estadual Djenal Tavares de Queiroz, com ações recorridas à recepção dos alunos sobre condutas e normas, acordo de convivência, entre outras dinâmicas que suscitaram emoções e sentimentos intra e interpessoal entre gestão, coordenação, equipe de professores, grupo Geração Jesus, funcionários e discentes. Em outra atividade, trabalhou-se o eixo Preservação e Organização do Acervo Documental da Escola, com o intuito de classificar os tipos de documentos, arquivo morto de ex-alunos, exprofessores e ex-funcionários, ofícios expedidos e diários em ordenação cronológica e alfabética, como também a oficina intitulada "Momento Autorreflexivo: o eu, o outro e o mundo", teve o objetivo de trabalhar valores da vida, leitura crítica sobre o respeito, as diferenças e limitações do outro e de si mesmo. Para a licencianda Margarida, a “[...] observação e a prática resultaram em pontos positivos e o estágio em gestão [promoveu] a construção de conhecimentos, provindos da experiência do campo e da formação docente, sendo consubstancial [para] a ressignificação da práxis pedagógica”.

Após o detalhamento dos projetos de intervenção desenvolvidos, cabe ressaltar as ações coletivas que ocorreram nas cinco escolas já apresentadas, destacando-se as atividades, 
o "Física Show na Educação Básica ${ }^{10 "}$ que ocorreu na UFS, no auditório e nas salas de aula do campus, tendo a participação, aproximadamente, de 180 crianças e adolescentes. Desse total, 75 foram do $1^{\circ}$ ano do ensino médio e 105 das turmas do $4^{\circ}$ e $5^{\circ}$ anos do ensino fundamental. Nessa ação, os graduandos do curso de Física realizaram atividades, como: apresentação de experimentos com estilo teatral; abordagem de fenômenos físicos, tendo como eixo norteador os temas da mecânica, termodinâmica, ondulatória e eletromagnetismo; interação da plateia com os monitores e os experimentos; desenvolvimento de suspense e curiosidade pela busca das explicações e dos significados subjacentes aos fenômenos físicos demonstrados.

A Oficina "Mundo Literário ${ }^{11 " ~}$ ofertada para 96 crianças dos anos iniciais do ensino fundamental, visando estimular o interesse, a imaginação e a descoberta pela leitura, instigando diferentes interpretações acerca dos textos estudados. Foram momentos significativos em que a criançada cantou, dançou, brincou, leu e interpretou.

A Oficina "A Hora do Conto ${ }^{12 "}$ promovida pelos bolsistas e voluntários do PET Educação, articuladas com as estagiárias, para 169 crianças da educação infantil e dos anos iniciais do ensino fundamental, teve como objetivos promover atividades voltadas ao desenvolvimento da linguagem e da expressão corporal, bem como estimular a utilização de literaturas infantis como proposta metodológica na prática educativa dos docentes.

A Oficina "Sapinho Equilibrista" ${ }^{13 "}$ trabalhou com 81 estudantes do $5^{\circ}$ ano, propondo atividades sobre as diferentes formas da Física e da tecnologia influenciarem a interpretação de mundo, estimulando a imaginação, a criatividade e a coordenação motora dos discentes. Foi uma oficina produtiva em que houve sinergia entre as crianças da educação básica, os petianos e as estagiárias, permitindo a (re)construção de conhecimentos e ressignificação de saberes.

A “Oficina de Negócios... 14" também atendeu a 37 educandos do $5^{\circ}$ ano e teve a finalidade de promover vivências voltadas ao campo do empreendedorismo e dos sonhos, visando ao desenvolvimento de habilidades criativas. As ações envolveram dinâmicas, roda

10 Registros disponíveis em: https://www.instagram.com/p/B_MovLIBbFT/?utm_source=ig_web_copy_link. Acesso em: 10 out. 2020.

11 Registros disponíveis em: https://www.instagram.com/p/B Lzwr_Bmj3/?utm_source=ig web copy link. Acesso em: 10 out. 2020.

12 Registros disponíveis em: https://www.instagram.com/p/B_K0UQehT-P/?utm_source=ig_web_copy_link. Acesso em: 10 out. 2020.

${ }_{13}$ Registros disponíveis em: https://www.instagram.com/p/B Ld7YOBZLB/?utm_source=ig web copy link. Acesso em: 10 out. 2020.

14 Registros disponíveis em: https://www.instagram.com/p/B_LIGFvBPlb/?utm_source=ig_web_copy_link. Acesso em: 10 out. 2020 
de conversa, discussão de conceitos, produções de cartazes, listas, desenhos e caça-palavras, contribuindo para a interação entre graduandas dos cursos de Administração e Pedagogia, aproximando a educação básica da universidade.

No tocante à avaliação e ao acompanhamento dos projetos de intervenção, o foco foi na coparticipação, visando ao desenvolvimento da crítica, da autonomia e do autoconhecimento, por meio da busca da qualidade dos cursos de formação inicial docente, em especial, do componente curricular Estágio Supervisado numa perspectiva contínua e de autoavaliação.

Assim, esse (re)pensar da avaliação na perspectiva qualitativa requer o movimento de (re)construção do sujeito situado no contexto da profissão docência. Dessa forma, os processos formativos conduzidos à luz dos cenários e momentos históricos requerem compreender novas peculiaridades e analisar as demandas entre o específico (estágio) e o indissociável (formação) dos saberes e fazeres experienciais. Nesse sentido, a leitura crítica da avaliação visa ao acompanhamento contínuo e possibilita construir significados no cotidiano da escola por meio de crenças, valores, saberes, conhecimentos, histórias de vida, representações, apropriações, angústias e anseios acerca do sentido de ser professor (PIMENTA, 2005).

Discute-se, então, como a avaliação converge à clareza de que a construção da identidade docente é o centro da formação inicial e continuada para agregar valores à experiência pessoal e ao saber pedagógico, corroborando com a interação entre alunos, sala de aula, escola e, principalmente, com as próprias itinerâncias.

\section{Formação na reflexão-ação-reflexão}

Este estudo apoiou-se na ideia de uma formação reflexiva que permite fazer uma avaliação dos saberes emergentes de uma caminhada em que o conhecimento formal não se limita a deduzir as práticas. Pelo contrário, o educador passa a equacionar sua práxis, escolher temáticas problematizadoras, propor alternativas de intervenção, criando estilos de debates, lidar com pessoas, acompanhar a apropriação de valores.

A análise da proposta interventiva em questão pautou-se na formação como atividade dialética, fruto de um processo de deliberação e estimulada pela interação professor-aluno e parceiros em diferentes situações cotidianas, fundamentadas no reconhecimento dos sentidos e significados do estágio e dos contextos profissionais na universidade, sustentando-se na premissa de que as ciências humanas necessitam de olhares e perspectivas plurais, numa 
relação entre aprendizagens e experiências, para a instituição de mecanismos de diálogo com a comunidade acadêmica e os gestores públicos.

Assim, considera-se que o estágio curricular supervisionado, com eixo central na gestão e coordenação pedagógica, do curso de Licenciatura em Pedagogia da UFS/Campus Professor Alberto Carvalho, permitiu a (re)construção da identidade e o desenvolvimento de conhecimentos e saberes relativos ao exercício profissão docente. Dentro dessa ótica, notou-se as inter-relações entre saberes experienciais e de formação profissional da docência, a difusão de práticas pedagógicas colaborativas e estímulo à produção de material didático interativo no âmbito da universidade e da escola básica.

AGRADECIMENTOS: Esta pesquisa recebeu financiamento da Coordenação de Aperfeiçoamento de Pessoal de Nível Superior (Capes) pelo Programa de Pós-graduação em Educação (PPGED/PROAP/UFS).

\section{REFERÊNCIAS}

BACHELARD, G. Os pensadores. São Paulo: Abril Cultural, 1978.

FRANCO, M. E. D. P. Gestão e modelos da educação superior. In: MOROSINI, M. (org.). Enciclopédia Pedagogia Universitária. Glossário. Brasília: Inep/Ries, 2006. v. 2. Disponível em: http://www.furb.br/proen/new/docs/Enciclopedia_Pedagogia.PDF. Acesso em: 15 ago. 2020.

LUCK, H. Fundamentação e princípios da educação e da gestão escolar. In: LUCK, H. Dimensões de gestão escolar e suas competências. Curitiba: Editora Positivo, 2009. p. 1530 .

MORIN, E. Os sete saberes necessários à educação do futuro. 3. ed. São Paulo: Cortez; Brasília, DF: Unesco, 2000.

NASCIMENTO, M. B. C.; OLIVEIRA, L. C. Eras da Pesquisa no Contexto das Redes Colaborativas na Educação Superior. Revista Educação Unisinos, v. 23, n. 4, out./dez. 2019.

OLIVEIRA, J. S. GUIMARÃES, M. C. M. O papel do coordenador pedagógico no cotidiano escolar. Revista Científica do Centro de Ensino Superior Almeida Rodrigues, Goiás, v. 1, n. 1, jan. 2013.

PIMENTA, S. G. Saberes pedagógicos e atividade docente. 4. ed. São Paulo: Cortez, 2005.

PIMENTA, S. G.; LIMA, M. S. L. Estágio e docência. 3. ed. São Paulo: Cortez, 2008. 
SACRISTÁN, J. G. Consciência e acção sobre a prática como libertação profissional dos professores. In: NÓVOA, A. (org.). Profissão de professor. Portugal: Porto, 1999. p. 63-92.

TARDIF, M. Saberes docentes e formação profissional. 17. ed. Petrópolis, RJ: Vozes, 2014.

TORRES, P. L.; IRALA, E. A. F. Aprendizagem colaborativa: teoria e prática. In: TORRES, P. L. (org.) Complexidade: redes e conexões na produção do conhecimento. Curitiba: SENAR - PR, 2014.

VIEIRA, S. R. Docência, gestão e conhecimento: conceitos articuladores do novo perfil do pedagogo instituído pela resolução CNE/CP N. 01/2006. Revista HISTEDBR On-line, Campinas, n. 44, p. 131-155, dez. 2011.

ZABALZA, M. A. O estágio e as práticas em contextos profissionais na formação universitária. São Paulo: Cortez, 2014.

\section{Como referenciar este artigo}

NASCIMENTO, M. B. C.; SANTOS, M. H. S.; GUEDES, J. T. Itinerâncias formativas: estágio e práticas em contextos de aprendizagens colaborativas. Revista Ibero-Americana de Estudos em Educação, Araraquara, v. 16, n. 3, p. 1807-1822, jul./set. 2021. e-ISSN: 19825587. DOI: https://doi.org/10.21723/riaee.v16i3.15131

Submetido em: 22/09/2020

Revisões requeridas em: 10/10/2020

Aprovado em: 15/11/2020

Publicado em: 01/07/2021 